\title{
Phenotip - a web-based instrument to help diagnosing fetal syndromes antenatally
}

\author{
Shay Porat ${ }^{1 *}$, Maud de Rham ${ }^{2+}$, Davide Giamboni ${ }^{3}$, Tim Van Mieghem ${ }^{4}$ and David Baud ${ }^{2}$
}

\begin{abstract}
Prenatal ultrasound can often reliably distinguish fetal anatomic anomalies, particularly in the hands of an experienced ultrasonographer. Given the large number of existing syndromes and the significant overlap in prenatal findings, antenatal differentiation for syndrome diagnosis is difficult. We constructed a hierarchic tree of 1140 sonographic markers and submarkers, organized per organ system. Subsequently, a database of prenatally diagnosable syndromes was built. An internet-based search engine was then designed to search the syndrome database based on a single or multiple sonographic markers. Future developments will include a database with magnetic resonance imaging findings as well as further refinements in the search engine to allow prioritization based on incidence of syndromes and markers.
\end{abstract}

Keywords: Syndrome, Prenatal ultrasound, Free web-based tool, Sonographic markers

\section{Findings}

\section{Background}

Many countries have incorporated ultrasound in routine prenatal care for fetal anomaly screening. When multiple fetal anomalies are found, a syndrome is often suspected. Some syndromes have a known genetic background and can be identified by invasive fetal testing with routine karyotyping and/or comparative genomic hybridization (e.g. Edwards syndrome or DiGeorge syndrome). Many others however, require specific gene sequencing or do not have a known genetic origin (such as Noonan syndrome or Fryns syndrome) and cannot be identified by routine genetic screening tests. Accurate prenatal identification or suspicion of a syndrome is therefore important to guide further testing and/or counseling. Given the large number of known syndromes [1] (over 6000) and a significant overlap in prenatal findings, antenatal differentiation is difficult. The $\mathrm{OMIM}^{\circ}$ (Online Mendelian Inheritance in Man) database [2], Orphanet [3], POSSUMweb [4] and London Medical Database [5] are searchable databases that allow links of phenotypic findings with (genetic) syndromes and may help in diagnosing syndromes. None of the database queries, however, include prenatal ultrasound

\footnotetext{
* Correspondence: shay.porat@gmail.com

${ }^{\dagger}$ Equal contributors

'Department of Obstetrics and Gynaecology, Hadassah University Hospital, Mount Scopus campus, Jerusalem, Israel

Full list of author information is available at the end of the article
}

findings (such as echogenic bowel or increased nuchal fold) in the search algorithm. Moreover, as these databases are mainly designed for postnatal use, they give great importance to markers that may not always be present or identifiable in the prenatal stage (such as failure to thrive, microcephaly or neurodevelopmental delay). Finally, these databases deal poorly with marker synonyms. As an example, the search terms "echogenic kidneys" and "hyperechogenic kidneys" yield 15 and 18 syndromes respectively in $\mathrm{OMIM}^{\circ}$ [2], but only three syndromes are shared by both searches.

The need for a freely available tool, useable in the prenatal period, brought us to design 'Phenotip', a free web-based searchable syndrome database, which is based exclusively on sonographic markers.

\section{Methods}

\section{Database design}

The Phenotip collaboration is an independent, international association between maternal-fetal medicine specialists with particular interest in prenatal diagnosis and a software engineer. The Phenotip database relies on a hierarchically structured "tree" of antenatal sonographic markers $(n=1140)$. Parent markers are organized by organ system and grow in resolution with every level of branching (daughter markers). For example, "face" branches into "eyes", "ears", "mouth and lips". "Mouth and 
lips" then further branches into "lip", "palate", "philtrum" and so on. Therefore, each marker has multiple parent and/or daughter markers. Marker synonyms have been defined to avoid confusion (e.g. talipes - clubfoot). Overall, 1140 sonographic markers are available, among them 130 markers have at least one synonym.
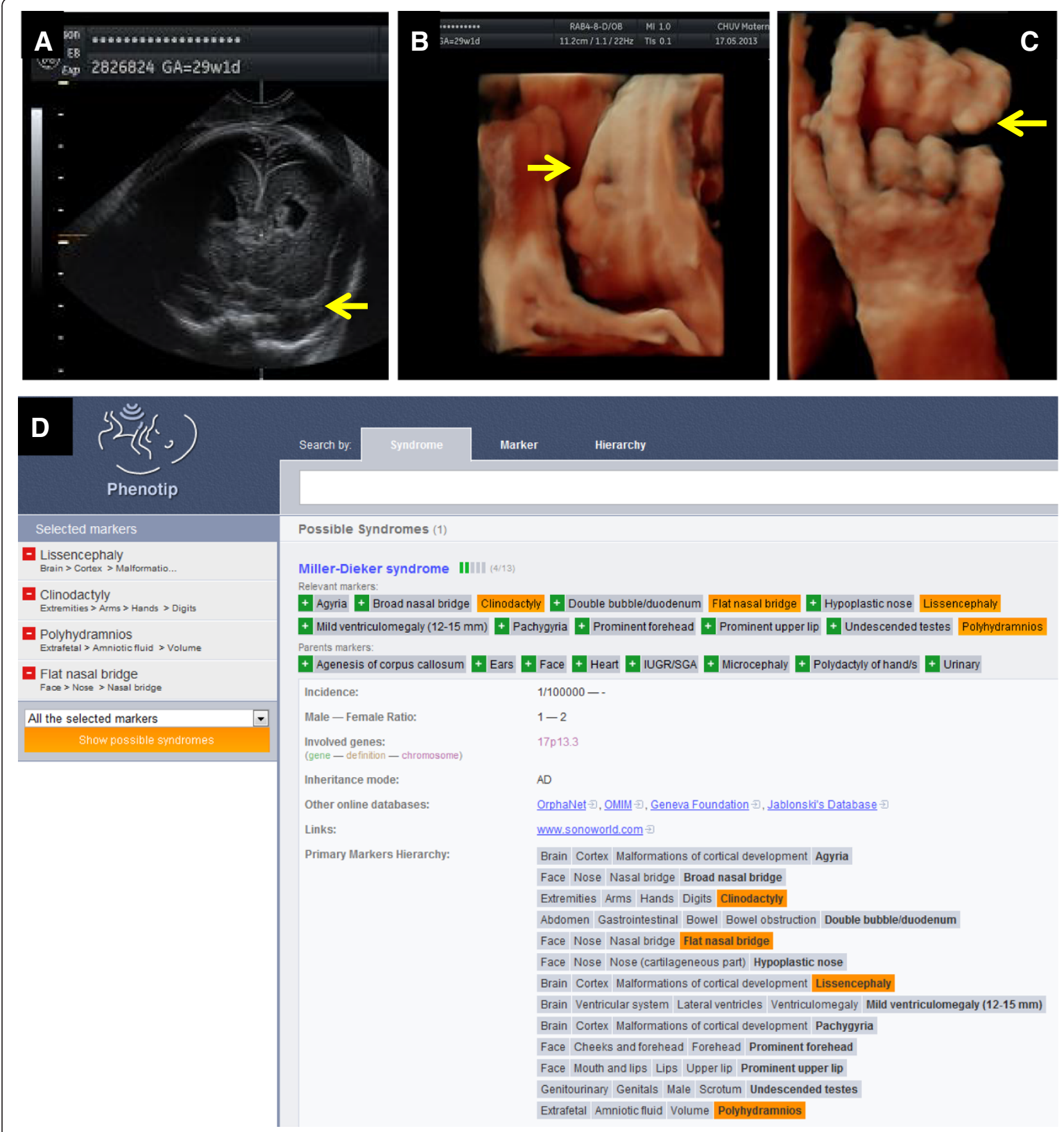

Figure 1 A 28 years old primigravida patient was admitted at 29 weeks gestation for short cervix and abdominal pain. Serologies, $1^{\text {st }}$ trimester screening and anatomy ultrasound at 20 weeks were all normal. On admission, ultrasound showed polyhydramnios, lissencephaly (A, coronal view), flat nasal bridge (B, sagittal 3D-view of the face) and clinodactyly (C, 3D-view of the hands). All images kindly provided by Yvan Vial, Lausanne-CHUV, Switzerland. Using the Phenotip.com database, these markers were suspected for a Miller-Dieker syndrome (D). In the Phenotip website, markers can be searched through a hierarchy tree (top right) or the marker search box (top middle). Each selected marker will appear on the left hand side of the screen under "selected marker" after clicking the green button. They can also be removed by clicking the red button. Differential diagnosis will appear after clicking the "show possible syndromes" button on the left hand side of the screen. Amniodrainage was performed, and CGH array confirmed a micro-deletion of locus p13.3 on chromosome 17 including LIS1gene. 
Markers are grouped into syndromes based on an extensive literature search. Only markers that were previously described in a peer reviewed publication as part of the antenatal sonographic phenotype of a proven syndrome were included in the database. Each syndrome is defined by its specific daughter markers, but also includes all hierarchically superior parent markers.

When this information was available, we also noted the incidence and inheritance pattern and male/female ratio for each syndrome. Weblinks to relevant overview articles or websites such as $\mathrm{OMIM}^{\circ}$ [2], Orphanet [3], Geneva Foundation [6], Jablonski's database [7] and SonoWorld [8] were added.

Information for each syndrome was registered by one editor, then peer-reviewed by at least one other editor. So far, we have collected literature on 329 of the most common syndromes.

\section{Searching the database}

The syndrome database is freely available through a web-based interface at www.phenotip.com. Users can search by syndrome name or by a combination of ultrasound markers.

When a specific marker is chosen, the search algorithm automatically includes all daughter markers of the chosen marker. Each level of the hierarchical tree of each specific organ system is thus considered. Choosing a parent marker will increase the sensitivity of the search while choosing a daughter marker will increase specificity. When a sonographic abnormality is not clearly defined, the involved organ can be selected, and hence all downstream markers would be considered. This is, for example, useful in cases of cardiac malformations, where one syndrome may present with a wide variety of heart lesions. Also, non-experienced sonographers might select the affected organ when they are unable to define the exact cardiac pathology.

Markers can either be selected from an expandable hierarchic tree or from a search box. Users can choose to search only syndromes including "all selected markers" or to search syndromes including either "one of the selected markers", thereby again increasing sensitivity or specificity, respectively.

\section{Results}

Since its inception in July 2013, the Phenotip database has logged 1215 sessions by 714 users with, among them, 136 regular visitors from 18 countries. The tool has allowed the identification of a sometimes-unsuspected diagnosis in many cases. A recent example suspected through our search algorithm and then confirmed by genetic analysis is presented in Figure 1.

Phenotip allows the search of differential diagnosis either by replacing a specific marker ("Flat nasal bridge") by a less specific marker ("Face"), or by removing a marker from the searching list. Table 1 provides an example based on markers used in Figure 1 (Miller-Dieker syndrome).

In addition, the database can offer guidance to the sonographer to find additional markers that differentiate between syndromes or genetic anomalies.

As this is a continuously evolving database (syndromes are being added on a daily basis), formal validation of sensitivity and specificity with validation against postnatal diagnosis has not been undertaken yet.

In order to test our database, all "cases of the week" from TheFetus.net were considered (380 cases, http:// sonoworld.com/TheFetus/Listing.aspx?Id=2). Inclusion

Table 1 Differential diagnosis found using 4, 3 and 2 markers from Figure 1

\begin{tabular}{ll}
\hline Markers inserted in Phenotip.com & Number of/diagnosis found with Phenotip.com (except Miller-Dieker Sd) \\
\hline $\mathbf{4}$ markers & - \\
Lissencephaly - Clinodactyly - Polyhydramnios - Face & \\
$\mathbf{3}$ markers & Microcephalic osteodysplastic primordial dwarfism \\
Lissencephaly - Clinodactyly - Polyhydramnios & Neu-Laxova Sd \\
Lissencephaly - Clinodactyly - Face & Rubinstein-Taybi Sd \\
Lissencephaly - Polyhydramnios - Face & \\
Clinodactyly - Polyhydramnios - Face & Microcephalic osteodysplastic primordial dwarfism \\
$\mathbf{2}$ markers & Neu-Laxova Sd \\
Lissencephaly - Clinodactyly & 5 other syndromes \\
Lissencephaly - Polyhydramnios & Rubinstein-Taybi Sd \\
Lissencephaly - Face & 16 other syndromes \\
Clinodactyly - Polyhydramnios & 44 other syndromes \\
Clinodactyly - Face & Polyhydramnios - Face
\end{tabular}


Table 2 Diagnosis found using prenatal images and corresponding markers from the Fetus.net

\begin{tabular}{|c|c|c|c|}
\hline Cases & Ultrasound markers in Fetus.net & $\begin{array}{l}\text { Diagnosis provided } \\
\text { in Fetus.net }\end{array}$ & Phenotip diagnosis \\
\hline 380 & Macrocephaly, short long bones, polyhydramnios, platyspondily & Schneckenbecken dysplasia & same diagnosis \\
\hline 378 & Hydrops, micromelia, ribs, narrow thorax, calcification of liver, polydactyly of hands & Greenberg dysplasia & same diagnosis \\
\hline 376 & Mega cisterna magna, micrognathia, pulmonary valve stenosis & DiGeorge sd & $\begin{array}{l}2 \text { diagnosis including } \\
\text { the correct one }{ }^{(1)}\end{array}$ \\
\hline 370 & $\begin{array}{l}\text { Ventriculomegaly, craniosynostosis, prominent forehead, midfacial hypoplasia, } \\
\text { macroglossia, renal cyst }\end{array}$ & Pfeiffer sd type II & same diagnosis \\
\hline 366 & Macrocephaly, abnormal profile, polydactyly, sandal gap & Greig cephalopolysyndactyly & same diagnosis \\
\hline 363 & $\begin{array}{l}\text { Macrocephaly, hypoplastic thoracic cage, platyspondyly, micromelia, brachydactyly, } \\
\text { bowed bones, low nasal bridge }\end{array}$ & $\begin{array}{l}\text { Thanatophoric dysplasia type } \\
\text { I }\end{array}$ & same diagnosis \\
\hline 361 & Low nasal bridge, trident hands, frontal bossing, rhizomelia, narrow thorax & Achondronplasia & same diagnosis \\
\hline 357 & Narrow thorax, bowed femurs, low set ears, clubfoot, nuchal edema, heart, retrognatia & Campomelic dysplasia & same diagnosis \\
\hline 345 & Kyphoscoliosis, hemivertebra, ribs & Jarcho-Levin sd & same diagnosis \\
\hline 331 & Ventriculomegaly, hypoplastic cerebellum, agyria & Walker-Warburg sd & same diagnosis \\
\hline 326 & $\begin{array}{l}\text { Flat nose, exophtalmia, cleft in soft palate, periventricular calcification, hypoplastic } \\
\text { thoracic cage }\end{array}$ & Raine sd & same diagnosis \\
\hline 321 & Cloverleaf shape, broad big toe, low nasal bridge, prominent eyes & Pfeiffer sd & same diagnosis \\
\hline 320 & Accessory auricle & Goldenhar sd & $\begin{array}{l}3 \text { diagnosis including } \\
\text { the correct one } \mathrm{e}^{(2)}\end{array}$ \\
\hline 318 & $\begin{array}{l}\text { Polydactyly of hands and feet, Rhizomelia/short femur and humerus, Ventricular } \\
\text { septal defect }\end{array}$ & Ellis van Creveld sd & same diagnosis \\
\hline 316 & Sacral agenesis, meningocele & Curranino sd & same diagnosis \\
\hline 314 & Depressed nasal bridge, frontal bossing, mitten deformity, corpus callosum & Apert sd & same diagnosis \\
\hline 308 & Hydrops, elbow pterygia, micrognathia & Multiple pterygium sd & same diagnosis \\
\hline 305 & Polydactyly of hands, micromelia, hypoplastic thoracic cage & Short rib polydactyly & same diagnosis \\
\hline 302 & Face, holoprosencephaly, anophtalmia, cleft lip & Cerebro-oculo-nasal sd & same diagnosis \\
\hline 290 & Abnormal profile, hydramnios, single umbilical artery, micrognathia & Treacher Collins sd & same diagnosis \\
\hline 286 & Soft tissu and bone hypertrophy, skin hemangiomas & Klippel-Trenaunay-Weber sd & same diagnosis \\
\hline 279 & Postaxial polydactyly of toes, ascites, hydrometrocolpos & McKusick-Kaufman sd & same diagnosis \\
\hline 277 & Skin, corpus callosum, cleft of soft palate & Pai sd & same diagnosis \\
\hline 272 & Hydramnios, micromelia, narrow thorax, short ribs, hepatomegaly & Caffey disease & same diagnosis \\
\hline 263 & $\begin{array}{l}\text { Rhizomelia/short femur /short humerus, postaxial polydactyly, ASD, Hypoplastic } \\
\text { thoracic cage }\end{array}$ & Ellis-Van Creveld sd & same diagnosis \\
\hline 257 & Hydrops, barrel shape chest, omphalocele, micromelia & Achondrogenesis type I & same diagnosis \\
\hline 153 & Kyphoscoliosis, neural tube defect, ventriculomegaly & Jarcho-Levin sd & same diagnosis \\
\hline 118 & Polyhydramnios, small/collapsed stomach, (previous hepatomegaly \& IUD) & Gaucher type II & $\begin{array}{l}4 \text { diagnosis including } \\
\text { the correct one }{ }^{(3)}\end{array}$ \\
\hline 117 & Micrognathia, Mesomelia forearms, Hypoplastic thumbs & Nager sd & same diagnosis \\
\hline 100 & Hydramnios, akinesia, talipes, face, hands & Myotonic dystrophy & same diagnosis \\
\hline 93 & Cloverleaf skull, vertebral body, broad big toes, broad thumbs, prominent eyes & Pfeiffer sd type II & same diagnosis \\
\hline 81 & Cloverleaf skull, micromelia, hydrocephalus, exophtalmia, hypoplastic thorax & Thanatophoric dysplasia II & same diagnosis \\
\hline 79 & Abdominal wall, ectopia cordis & Pentalogy of cantrell & same diagnosis \\
\hline 77 & IUGR, generalized edema, single umbilical artery (SUA) & Monosomy X & same diagnosis \\
\hline 75 & $\begin{array}{l}\text { Hypertelorism, dandy walker, dilated aorta, pulmonary valve stenosis, rocker bottom } \\
\text { foot, clinodactily, pectus excavatum, SUA }\end{array}$ & Trisomy 9 & same diagnosis \\
\hline 71 & Hypospadia, nasal bone hypoplasia, micrognathia & Trisomy 21 & same diagnosis \\
\hline 67 & Clubfoot, limbs, sacrum & Atelosteogenesis type II & same diagnosis \\
\hline 65 & Coarctation of aorta, unilateral hypoplasia of cerebellum, hemangioma & PHACE association & same diagnosis \\
\hline
\end{tabular}




\section{Table 2 Diagnosis found using prenatal images and corresponding markers from the Fetus.net (Continued)}

\begin{tabular}{|c|c|c|c|}
\hline 48 & Thick placenta, IUGR, anhydramnios/oligohydramnios & Trisomy 16 & $\begin{array}{l}2 \text { diagnosis including } \\
\text { the correct one }\end{array}$ \\
\hline 44 & IUGR, polyhydramnios, increased NT, kydneys, broad thumbs, short long bones & Rubinstein Taybi Syndrome & same diagnosis \\
\hline 41 & Holoprosencephaly, pectus excavatum, clenched hands, akinesia & $\begin{array}{l}\text { Holoprosencephaly-fetal } \\
\text { akinesia sequence }\end{array}$ & same diagnosis \\
\hline 40 & Micrognathia, skin & Goldenhar sd & $\begin{array}{l}5 \text { diagnosis including } \\
\text { the correct one }\end{array}$ \\
\hline 38 & Hydrocephalus, thin upper lip, mega cisterna magna, extremities & Fryns sd & $\begin{array}{l}5 \text { diagnosis including } \\
\text { the correct one }\end{array}$ \\
\hline 34 & $\begin{array}{l}\text { Polyhydramnios, nuchal thickening, micrognathia, poor ossification of ribs, } \\
\text { receding forehead }\end{array}$ & Cerebro-costo-mandibular sd & same diagnosis \\
\hline 31 & Micrognatia, renal hypoplasia, IUGR & Wolf-Hirschhorn sd & same diagnosis \\
\hline 30 & Skin hemangiomas, renal & Klippel Trenaunay Weber sd & same diagnosis \\
\hline 23 & $\begin{array}{l}\text { Choroid plexus cyst, limbs, clenched hands, overlapping fingers, clubfoot, } \\
\text { nuchal thickening }\end{array}$ & Pena Shokeir sd & $\begin{array}{l}2 \text { diagnosis including } \\
\text { the correct one }\end{array}$ \\
\hline 20 & $\begin{array}{l}\text { Short limbs, overlapping fingers, clinodactyly, hypoplastic kidneys, } \\
\text { ventriculomegaly, heart }\end{array}$ & Smith Lemli Opitz sd & same diagnosis \\
\hline 12 & Omphalocele, bladder extrophy, neural tube defect, clubfoot & OEIS complex & same diagnosis \\
\hline 1 & Oligohydramnnios, heart, micrognathia, placenta, sandal gap & Triploidy & same diagnosis \\
\hline $\begin{array}{l}{ }^{(1)} \mathrm{Tr} \\
{ }^{(2)} \mathrm{C} \\
{ }^{(3)} \mathrm{Tr} \\
{ }^{(4)} \mathrm{Tr} \\
{ }^{(5)} \mathrm{Cr} \\
{ }^{(6)} \mathrm{Fr} \\
{ }^{(7)} \mathrm{Pe}\end{array}$ & $\begin{array}{l}\text { ny } 18, \text { DiGeorge sd. } \\
\text { e sd, Goldenhar sd, Branchio-oto-renal sd. } \\
\text { ny } 18 \text {, Gaucher type II, VACTERL, Pallister Killian, if hepatomegaly considered, only Gaucl } \\
\text { ny } 16, \text { Meckel-Gruber sd type I. } \\
\text { lia de Lange sd, Multiple pterygium sd, Goldenhar sd, Neu laxova sd, trisomy } 9 . \\
\text { sd, Trisomy } 13-18-21 \text {, Joubert sd. } \\
\text { shokeir, Trisomy } 18 . \\
\text { ison between Phenotip and post-natal diagnosis. }\end{array}$ & II sd. & \\
\hline
\end{tabular}

criteria were syndromes only. Exclusion criteria were cases with a unique organ involved (mainly bone and heart). All the remaining cases were considered $(n=50$, see Table 2$)$. Only prenatal markers based on ultrasound images from the Fetus.net website were used in Phenotip. In 12 cases (24\%), one of the markers used was only present in the prenatal period (such as hydramnios, single umbilical artery). Among 50 unselected cases, 43 (86\%) were found as correct and unique diagnosis. In 7 cases (14\%), 2-5 diagnoses were identified, always including the correct diagnosis. By using all the data provided in the Fetus.net (karyotype, recurrence), many of these multiple diagnoses can be excluded. We are currently adding new Phenotip functions such as "known karyotype" and "previous case in the family" to increase specificity (Table 2).

Finally, the database is already designed to incorporate the relative frequency of each marker in each specific syndrome, so in the future the search will have even greater specificity and will use a Bayesian approach.

\section{Conclusion}

We here describe the development of a searchable database of fetal syndromes. In contrast to other (commercially) available databases, this database only relies on antenatally diagnosable markers and does not include often subtle, postnatal findings.
We feel that this database may help both more and less experienced sonographers, obstetricians, geneticists and fetal medicine specialists in reaching the diagnosis of a fetal syndrome antenatally. Indeed, medicine involves large amounts of data that usually have to be exploited jointly. Given the limitations of the human brain, complex mathematical algorithms or Bayesian networks [9], integrating all available information can obtain better diagnostic accuracy.

Computer assisted diagnosis is already put in clinical practice on a daily basis in other branches of obstetrics and gynecology. Examples of this include prenatal screening for trisomy 21 [10], outcome prediction of pregnancies of unknown location [11] and discriminating between benign and malignant ovarian masses [12].

This database certainly does not replace expert fetal care providers as it still requires the input of accurate findings and will often only generate a differential diagnosis, which then needs to be explored further. Moreover, dealing with computed knowledge and software as tools for diagnosis does not substitute communication skills and empathy when facing patients.

This project is a work in progress and the number of syndromes included in the database will be further updated. Future developments will include the addition of magnetic resonance imaging markers [13] as well as 
further refinements in the search engine to allow prioritisation based on incidence of syndromes and markers. Moreover, we will add postnatal findings and information to each syndrome.

We anticipate that the growing use of advanced technologies (such as chromosomal microarray [14] or exome sequencing [15]) for the prenatal diagnosis of genetic alterations that are associated with sonographic abnormalities will discover novel, currently unknown, syndromes. This will further enhance the linkage between specific sonographic findings and the concomitant genomic alteration. As data gathers, we will incorporate those novel syndromes and information into the database. With this database, we hope to facilitate antenatal diagnosis of fetal syndromes and improve patient care.

\section{Presentation information}

These data were presented at:

- $32^{\text {sd }}$ International Fetal Medicine and Surgery Society (IFMSS), Jerusalem, Israel - May 19-24, 2013 (oral presentation)

- $13^{\text {th }}$ World Congress in Fetal Medicine, Fetal Medicine Foundation, Nice, France, June $29^{\text {th }}-$ July $3^{\text {rd }}, 2014$, (poster presentation)

Competing interest

The authors declare that they have no competing interests.

\section{Authors' contributions}

All authors were involved in drafting the article or revising it critically for important intellectual content and all authors approved the final version. Database conception and design: SP, TVM, DB. Web-based tool: DG. Acquisition of data: MDR, SP, TVM, DB. Analysis and interpretation of data: MDR, SP, TVM, DB.

\section{Acknowledgments}

We thank Dan Porat for his contribution with the technical aspects of the Phenotip database and search algorithm. We thank Sam Vasilevsky, Karine Lepigeon and Françoise Damnon for critical review of the manuscript. David Baud is supported by the "Fondation Leenaards" through the "Bourse pour la relève académique".

Tim Van Mieghem is supported by the Clinical Research Fund (KOF/KOOR) of the University Hospitals Leuven, Leuven, Belgium.

\section{Author details \\ 'Department of Obstetrics and Gynaecology, Hadassah University Hospital, Mount Scopus campus, Jerusalem, Israel. ${ }^{2}$ Materno-Fetal and Obstetrics Research Unit, Department of Obstetrics and Gynaecology, University Hospital, Lausanne, Switzerland. ${ }^{3}$ TechCare.ch, Geneva, Switzerland. ${ }^{4}$ Department of Obstetrics and Gynaecology, Division of Woman and Child, University Hospitals Leuven, Leuven, Belgium.}

Received: 18 September 2014 Accepted: 26 November 2014 Published online: 10 December 2014

\section{References}

1. Benacerraf BR: Ultrasound of Fetal Syndromes. Secondth edition. Philadelphia: Churchill Livingstone; 2007

2. Johns Hopkins University. $\mathrm{OMIM}^{\circledast}$ Online Mendelian Inheritance in $\mathrm{Man}^{\circledast}$. Available at: http://www.omim.org. Retrieved August 8, 2014

3. INSERM US14. Orphanet: The portal for rare diseases and orphan drugs. Available at: http://www.orpha.net/consor/cgi-bin/index.php. Retrieved August 8, 2014
4. Murdoch Childrens Research Institute. POSSUMweb Pictures Of Standard Syndromes and Undiagnosed Malformations. Available: http://www. possum.net.au. Retrieved August 8, 2014

5. Winter R, Baraitser M. London Medical Database. Available at: http://www. Imdatabases.com. Retrieved August 8, 2014

6. Geneva Foundation for Medical Education and Research. Available at: http://www.gfmer.ch. Retrieved August 8, 2014

7. Jablonski S. Jablonski's database. Available at: http://www.nlm.nih.gov/ archive/20061212/mesh/jablonski/mesh/jablonski/syndrome_db.html. Retrieved August 8, 2014

8. Ray E, Goldberg BB, Merritt CRB, Waldroup L. Sonoworld. Available at: http://sonoworld.com. Retrieved August 8, 2014

9. Van Calster B, Nabney I, Timmerman D, Van Huffel S: The Bayesian approach: a natural framework for statistical modeling. Ultrasound Obstet Gynecol 2007, 29(5):485-488.

10. Wright D, Syngelaki A, Bradbury I, Akolekar R, Nicolaides KH: First-trimester screening for trisomies 21, 18 and 13 by ultrasound and biochemical testing. Fetal Diagn Ther 2014, 35(2):118-126.

11. Van Calster B, Condous G, Kirk E, Bourne T, Timmerman D, Van Huffel S: An application of methods for the probabilistic three-class classification of pregnancies of unknown location. Artif Intell Med juin 2009, 46(2):139-154.

12. Van Holsbeke C, Van Calster B, Bourne T, Ajossa S, Testa AC, Guerriero S, Fruscio R, Lissoni AA, Czekierdowski A, Savelli L, Van Huffel S, Valentin L, Timerman D: External validation of diagnostic models to estimate the risk of malignancy in adnexal masses. Clin Cancer Res Off J Am Assoc Cancer Res 2012, 18(3):815-825.

13. Sepulveda W, Ximenes R, Wong AE, Sepulveda F, Martinez-Ten P: Fetal magnetic resonance imaging and three-dimensional ultrasound in clinical practice: applications in prenatal diagnosis. Best Pract Res Clin Obstet Gynaecol oct 2012, 26(5):593-624.

14. Dhillon RK, Hillman SC, Morris RK, McMullan D, Williams D, Coomarasamy A, Kilby MD: Additional information from chromosomal microarray analysis (CMA) over conventional karyotyping when diagnosing chromosomal abnormalities in miscarriage: a systematic review and meta-analysis. BJOG 2014, 121(1):11-21.

15. Biesecker LG, Green RC: Diagnostic clinical genome and exome sequencing. N Engl J Med 2014, 370(25):2418-2425.

doi:10.1186/s13023-014-0204-7

Cite this article as: Porat et al:: Phenotip - a web-based instrument to help diagnosing fetal syndromes antenatally. Orphanet Journal of Rare Diseases 2014 9:204.

\section{Submit your next manuscript to BioMed Central and take full advantage of:}

- Convenient online submission

- Thorough peer review

- No space constraints or color figure charges

- Immediate publication on acceptance

- Inclusion in PubMed, CAS, Scopus and Google Scholar

- Research which is freely available for redistribution 